\title{
The Valuation And Reporting Of Reputation Risk Management Capability
}

Janek Ratnatunga, (E-mail: janek.ratnatunga@buseco.monash.edu.au), Monash University, Australia Michael Vincent, (E-mail: michael.vincent@buseco.monash.edu.au), Monash University, Australia

\begin{abstract}
The Financial Statements prepared and audited in today's economic environment can be traced to the industrial era, when tangible assets such as machinery were the engines of growth. In this era, financial accountants endorsed or invented rules based on the historical cost doctrine that yielded values which had no counterparts in commercial reality - often book valuations were sheer fictions, and thus managing the risk associated with those valuations became a meaningless exercise. This was especially the case when intangible assets such as an organisation's Brand Equity and Reputation were kept off the Balance Sheet, thus making the valuations even more fictitious. This has resulted today in knowledge-economy companies reporting book values widely divergent of market values. These fictitious financial reports were then audited, and the auditors were paid well by the preparers of the statements to hold that the statements gave a true and fair view of the state of affairs of the company. When some of these companies failed spectacularly due to the mismatch between commercial reality and reported values, the reason for failure was pinpointed to the irreparable damage to the company's reputation due to the lack of adequate risk management procedures, resulting in a failure traced to an organisation's products, services, information systems or external auditors. Since the spectacular collapses of Enron and WorldCom in the international stage, many countries have introduced either mandatory or voluntary corporate governance procedures. In the USA, SOX 404 makes mandatory the reporting of all significant risks in a company's annual reports, albeit outside of the financial statements, as an off-balance sheet item. This paper argues that the overriding reason for governance is ultimately the safeguarding of an organisation's reputation, and that this requires an integrated approach where the 'accountees' (corporations), and its investors and regulators are provided with appropriate information by the 'accountors', i.e. the accounting profession. It also argues that although the current professional accounting standards result in financial statements that are not adequate for the proper governance, an integrated approach can be taken where reputation risk can not only be managed and valued; it can also be incorporated in these financial statements. The paper provides a valuation model based on the premise that risk management should not be based on what the organisation has, but instead what the organisation can do, i.e. its capability to manage and enhance its reputation in order to ultimately generate incremental future cash flow. It then suggests an approach that auditors can take to determine its strategic capability of sustaining and generating value via reputation enhancement. Finally, the paper considers the role of the Risk Manager, and how an empowered open-book approach to communicating and financial reporting can provide significant motivational benefits in risk reduction and reputation enhancement that ultimately result in increased value.
\end{abstract}

\section{INTRODUCTION}

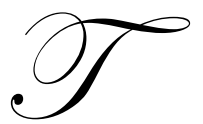

he age of the corporation (since 1850) led to the enormous emphasis on the determination of profit hence the acceptance of arbitrary cost allocations. Now the focus has widened. Owners, investors, creditors, bankers, government now all need leading indicators. Accounting - especially financial accounting - is still preoccupied by lagging indicators. For example: 


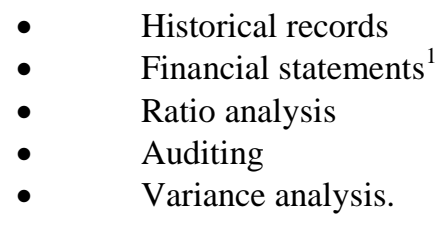

Such a preoccupation with the past is akin to "navigating by looking at the wake created by the ship". This is only possible, if one is sure one is going in the right direction, and if one is sure there will be no unexpected ships, icebergs and floating debris crossing the ship's path. Such a backward looking preoccupation is unacceptable to corporate risk managers who must look ahead to evaluate the impact of future conditions on the continued viability of their organisation.

This paper argues that the overriding reason for governance is ultimately the safeguarding of an organisation's reputation, and that this requires an integrated approach where the 'accountees' (corporations), and its investors and regulators are provided with appropriate information by the 'accountors', i.e. the accounting profession. Unfortunately, the 'accountors' have relied for the last 500 years on the financial accounting reporting model, last significantly updated only during the period of the 'industrial revolution'. The resulting information provided by this model has, inevitably, caused many a 'Titanic' in the corporate world, especially in the last two decades.

In the early 1990s, corporate bankruptcy increased to an all time high around the world (Webb, et. al 1991). During this period, media reports regarding myopic auditors were almost as numerous as those regarding deceitful directors (Kohler, 1991). Accountants and Auditors were seen as the 'risk managers' of these firms, but were seen as not having performed their statutory duties. What was the accounting profession's response at that time? Increased regulation, increased compliance, increased accounting standards. "That should fix the problem", was the belief, and that this should lead to a significant reduction in spectacular collapses, was the expectation (Tweedie, 1991). Then, 10years later, came Enron, WorldCom, Ansett, OneTel, Parmalot. Collapses in all parts of the world. What is the accounting profession's response this time? Again, increased regulation, increased compliance, increased accounting standards, but with a twist. The financial accounting profession now claims that the panacea is "convergence" via the International Financial Reporting Standards (IFRS), i.e. one set of international accounting standards for the world. This IFRS response has, however, been taken without any research evidence to indicate that had there been only one set of standards at the time, this would have prevented the Enron, WorldCom etc. collapses.

The financial accounting profession has pushed the IFRS bandwagon as it is in their interest do so. As a result, their compliance business has more than doubled. A new breed of auditor has evolved, the "IFRS Compliance Auditor". Having obtained acceptance of IFRS from organisations such as the World Bank, sovereign governments have been pressured to ensure that their country's accounting bodies adopt IFRS, despite the issues that brought about IFRS being totally irrelevant to many developing countries. However, non-compliance could result in World Bank and other funding being withheld, so many developing countries have no option but to accept IFRS.

The more recent collapses have been of such magnitude, however, that the financial accounting profession and its IFRS reports are no longer entrusted with the sole reporting role in the performance of an organisation and the management of its value. The legal and finance profession via legislation and stock market regulators have also become involved; in some countries with mandatory regulation such as the Sarbanes Oxley (SOX) 404 in the USA. In other countries, the regulation is still voluntary, such as the Australian Stock Exchange's 10-point Corporate Governance Guidelines. For example, SOX 404 requires CFOs and CEOs to sign-off on the accounts as well. The role of the professional risk manager has now become a key to ensuring an organisation's long-term survival.

\footnotetext{
${ }^{1}$ This includes the cash flow statement, although such statements are much harder to manipulate. If companies revert to only cash flow statements, and audit the 'capability' of the organisation to generate future cash flow, i.e. via a strategic audit, the fictitious aspects of their reports will be significantly reduced.
} 
During the prevailing years between the spectacular collapses of the early 1990s and those of the early 2000s, concerns other than good corporate governance have also arisen. Reports were demanded on the impact of the actions of corporations on the environment, and on society. "Triple bottom line" is thus the reporting extension of the concept of sustainable development, which has been defined as "development that meets the needs of the present world without compromising the ability of future generations to meet their own needs". In the modern firm, therefore, Risk Management is very concerned not only with ensuring good corporate governance, but also in managing all three "bottom lines", namely how an organisation's economic, environmental and social performance maintains its reputation and ultimately its value.

\section{NEW APPROACHES TO RISK REPORTING}

From the above discussion, it can be seen that, increasingly, the providers of "capital", (i.e. the accountees) require far more information than the financial performance of its past activities to ensure that the reputation and value of their investments are being properly managed - they are becoming far more preoccupied with the future safety and performance of their investments. Further, governments (infrastructure); employees (human assets) and environmental groups (the Earth) are also claiming to be providers of capital, thus also wanting to be regarded as 'accountees'. This requires the provision of:

- $\quad$ Strategic and control information;

- $\quad$ Future-orientated and historical information;

- $\quad$ Financial and non-financial information;

- $\quad$ Profit-motivated and socially-responsible information;

- $\quad$ Timely and accurate information; and

- Motivational information

In an informational-era enterprise, the distinctions between white and blue-collar workers are far less pronounced, as all workers become knowledge workers. The role of a risk manager, management accountant (or any other informational professional) is to manipulate the available data and provide the (often future oriented) information in terms of the new measures demanded by these knowledge workers.

Consideration should be given to the nature, recognition, and measurement of information-era assets. The engine(s) that drive information-era enterprises include knowledge, innovation, communication, learning, and innovative abilities. However, such assets are still systematically excluded from our industrial-era balance sheets; thus understating the total "capital" of the enterprise. Therefore, currently "short-term monetary capital maintenance" is the focus instead of "long-term comprehensive capital maintenance". This also provides temptation to managers to reduce some of these assets for the sake of short-term earnings. For example, in earlier times, advertising was seen as an expense rather than a variable that enhances a Brand's future earnings potential (i.e. an asset). Thus there was a temptation amongst managers to increase short-term profit by reducing the advertising spend. Today's managers may similarly reduce the maintenance carried out on a tangible asset (e.g. aircraft), or reduce the training given to an intangible asset such as a knowledge worker (e.g. aircraft maintenance technician). If as a consequence the aircraft crashes, this could irreparably damage the reputation of the airline. In certain instances, such cost savings (e.g. on safety equipment for workers) could result in jail terms for directors.

One significant area in which the traditional financial accounting measurement model fails is in the area of valuing intangibles. Thus if we are to develop a new accounting model for a new age, we need new types of "measurements", for both tangible and intangible assets in order for organisations to meet the challenges present at the corporate, national and international levels, especially in the areas of decision-making, performance evaluation, risk management and organisational valuation.

Figure One illustrates the issues involved. The available tangible and intangible assets are the preconditions required for the inducement of sales (the consequences). These preconditions act via an intermediate variables of contextual capability and brand capability (or organisational reputation) to generate both present and future sales potential. The present value of such sales potential is therefore the "value" of the contextual capability that gives rise to the brand/reputation capability. It is this brand/reputation capability which must be managed. 
Preconditions

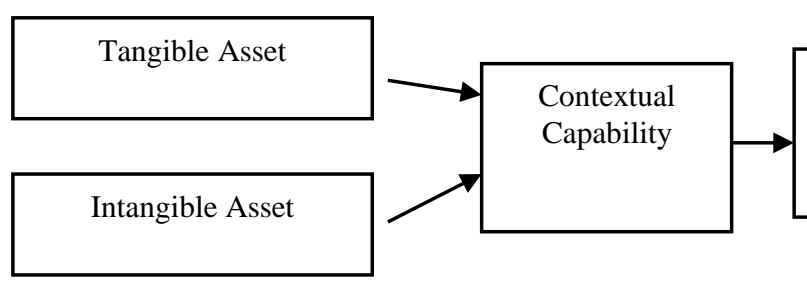

Intermediate Variables

Consequences

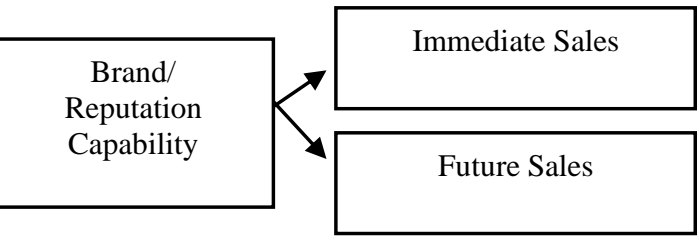

The problems associated with implementing these new measurements are immense. For example, in the marketing communications area, even if tangible assets (such as the sales force, billboards, trade promotions counters, samples, catalogues, etc) and intangible assets (brands, logos, trade marks, advertising jingles, slogans, patents and copyrights $)^{2}$ can be valued, what is especially difficult in practice is the valuation of the associated tacit knowledge and judgment required to combine these differing assets to enhance the capability (and ultimately value) of the organisation (see Ratnatunga, et al. 2004).

At this point it is important to contrast tangible and intangible assets, contextual capability, brand (reputation) capability and the resultant capability value. Assets are "what one has", much like a Ferrari racing car (tangible asset) or Michael Schumacher's driving skills (intangible asset). Contextual Capability is what can be achieved in a particular situation (or "what one can do") when these asset categories are combined in a contextual situation, i.e., win the World Championship. Brand/Reputation Capability is the esteem perception created in potential customers' minds about the Ferrari brand as a consequence of winning the world championship. Capability Value is the economic value of the capability (i.e. the current and future monetary value to Ferrari via sales, having a Brand Reputation of winning the formula one championship). Any diminution of that reputation due to poor risk management techniques, ultimately results in the diminution of an organisation's value, and if this process goes unchecked, or has a significant avoidable disaster, an Enron type corporate collapse could result.

It is clear that in implementing current GAAP, financial professionals face a dilemma when it comes to valuing intangibles. This is because they want financial statements to be both reliable and relevant. Reliability is easy to achieve, but relevance is not. This is especially true when it comes to knowledge-based organisations such as Microsoft, because the intangible assets are not referenced in their statements, yet these assets are highly relevant to its stakeholders.

The Accounting Profession believes that financial statements must be 'reliable', i.e. they must be both accurate and supportable. Such reliability would suggest that if two different accountants prepared the same statements, the two answers should come close to each other, particularly if they each relied on the same hard evidence. This is why the profession has worked hard over the last 30 years to issue 'Accounting Standards' to ensure that as much subjectivity as possible is removed in their preparation. Unfortunately the result is that we have financial statements that report a company having a book value widely different to the value the market places on it.

\footnotetext{
${ }^{2}$ The definition of an asset used in this paper, is that of a cost incurred which has a "future economic benefit". Current financial accounting reporting standards will not recognise some of these costs as assets, such as the costs of maintaining a well-trained and motivated sales force and much of advertising costs. Many of such costs are considered has having only single period economic benefits, and thus are expensed in financial accounting reports. However, Ratnatunga et al. (2004) argue that such costs enhance the strategic capability of an organisation and thus should be considered as capability assets for future oriented decisionmaking.
} 
Accounting standards achieve 'reliability' by requiring evidence of an arms-length transaction between two parties. Thus when an organisation buys an asset, such as a truck, from an external supplier, and cash changes hands, this is good evidence that the organisation now has an asset that exists (and in most cases can be physically verified, thus increasing reliability) and that a sale has been made by the supplier company, and thus a profit (or loss) can be recognised by it.

Despite the GAAP in most countries recognising that the purpose of financial statements is to also provide investors and creditors with information about future earnings prospects and cash flows (i.e. be relevant) in the case of intangible assets, because an 'arms length' transaction has not occurred (and thus their valuation fails the 'reliability' test), these are kept off the balance sheet, or the amounts paid in creating them are expensed. However, as argued before, intangible assets are equally as relevant to an understanding of the organisation's strategic objectives. Ratnatunga, et al. (2004) proposes a valuation method to convert all such strategic expenses to assets values. The ultimate result is a Strategic Balance Sheet as illustrated in Figure Two incorporating both tangible and intangible asset capability values.

\section{RISK MANAGING THE TRIPLE -BOTTOM LINE}

TBL Reporting arose out of the sustainability agenda which was long understood as Environmental Reporting", i.e. an attempt to harmonise the traditional financial bottom line, with the environmental bottom line. However, it is turning out to be not a double bottom-line, but instead a 'triple bottom line', focusing on:

\section{- $\quad$ Economic prosperity \\ - $\quad$ Environmental quality, and also \\ - $\quad$ Social justice (overlooked in the past)}

To achieve the balance implicit in the 'triple bottom line' concept, we not only need: new forms of accountability, but also new forms of accounting. This does not mean that every aspect of a company's performance can - or should - be reduced to a 'common currency' of money values. However, if we are to manage a given company's performance effectively, we need to be able to measure it. TBL reporting provides a bridge between the conventional or mainstream means of demonstrating corporate success, and the more unconventional but increasingly demanding call for acceptance of a corporation's implied contract with society.

There is ample evidence of mainstream adoption of ethical investment principles, both in Australia and worldwide, such as the:

- $\quad$ Establishment of the Dow Jones Sustainability Index.

- $\quad$ Publication of stand-alone social reports by organisations such as The Body Shop, Shell (UK), and BP (UL).

- Publication of sustainability reports by organisations such as Baxter International, The Body Shop, Electrolux, Shell, Ford Motor Company, British Airways, General Motors and TXU Europe.

- $\quad$ Establishment of ethical investment funds in Australia by Rothschild Australia, Westpac, Tower, AMP, HESTA, UniSuper and VicSuper.

- $\quad$ Reported assets in ethical investments in the USA and UK growing by 50\% per annum for the past decade with \$US2.16 trillion invested in ethical funds. 
The question that must be asked, therefore, is, "What comprises an organisation's social responsibility?" Most organisations acknowledge today that they have an implied social contract, i.e. a "community licence to operate". Logic dictates that a corporation's acceptance of its part in an implied social contract then extends to an acceptance of accountability for breach of that social contract. In many organisations, this accountability rest in the hands of the Risk Manager who must ensure that this implied social contract is not breached.

Some examples of the elements of an organisation's environmental and social responsibilities are found in its record pertaining to the:

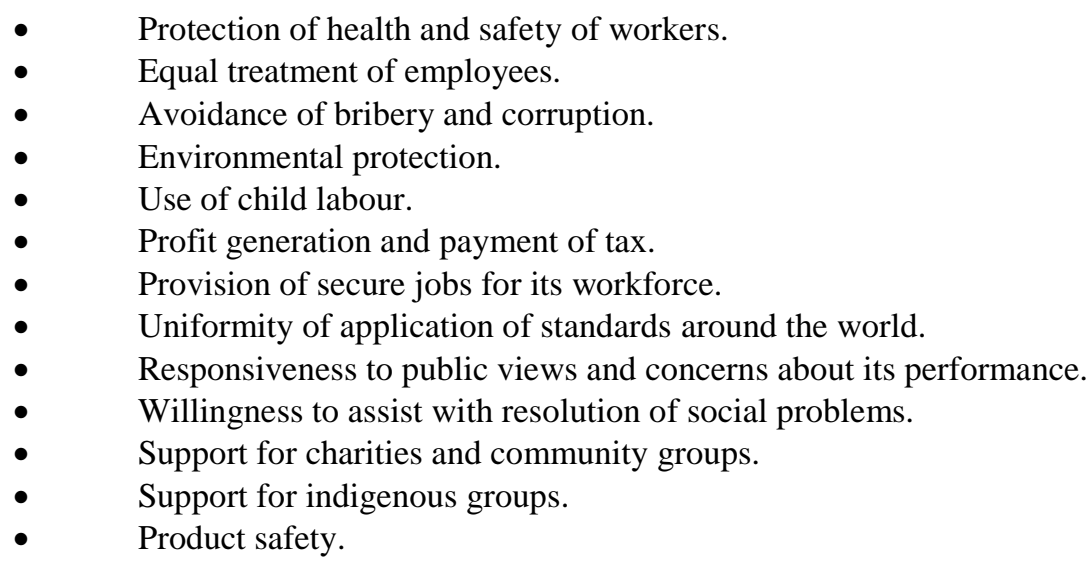

In most, if not all of the above areas, the ultimate value to an organisation in meeting its environmental and social responsibilities would be the result of contextual capability that arises when the required preconditions are present (see Figure One). For example, the protection of health and safety of workers requires not only a safe working environment (e.g. with such tangible assets as reliable machinery, clean buildings etc.), but also on such intangible assets as properly trained workers. Thus the costs incurred by an organisation in investing in such tangible and intangible assets, must be compared with the benefits (consequences) in terms of current and future sales that such investments will bring due to an enhanced Brand/Reputation capability.

The likelihood that a credible standard for simultaneously measuring and reporting against all three 'bottom-lines' will be available in the near term is good, given, the continued demand for "Sustainable development", the extent of public scrutiny of organisational performance reports, and the numbers and standing of corporations that have already published social and ethical reports. The more that organisations report against the three bottom lines, the more its reputation and ultimately its value can be enhanced.

\section{CORPORATE GOVERNANCE AND RISK MANAGEMENT}

Corporate governance as a serious and urgent research issue has become established over the last few especially after the public spectacle of failures of once-esteemed public firms during the first four years of the new century. As evidenced by the increasing number of codes of best practice developed by leading international bodies such as the OECD, the Commonwealth and CalPERS (refer Demirag et al. (2000) for a fuller list of publications), stock exchanges, securities commissions, corporate governance reform has now become a key global issue. Not only do factors such as the increasing globalisation of financial markets, the growth in multinational corporations and regional economic developments motivate the need for good corporate governance in the face of recent spate of large corporate collapses in Western economies such as the cases of HIH Insurance in Australia, Parmalat in Europe, Enron and WorldCom in the United States (U.S.). Whilst these clearly signal the urgency for significant improvements in corporate accountability and reporting, the issue of corporate governance is even more important in transitional economies (see Roland, G., 2000). Attention to corporate governance is largely motivated by public interest in the economic health of corporations and society in general. However, the concept of corporate governance has got various dimensions as it potentially covers a large number of distinct economic, legal and social phenomena. 
No sooner has the world learned fresh lessons about good governance rules to prevent the repeat of failures of institutions to safeguard investors, new cases have emerged that cast doubt that the lessons of previous three years have been learned. A number of new cases have emerged - Parmalat in 2004 in Europe - which highlight the need for continued research interest on governance failures as a worldwide problem. New laws and regulations as well as oversight institutions have been established to improve governance. Much regulation revolves around the reporting requirements. Ratnatunga and Ariff (2005) also argue that investor protection could also be safeguarded by closer scrutiny of the vast store of information available on each of the some 36,000 public firms on the stock markets.

Although corporate governance issues have been seen historically to be the province of lawyers and finance professionals; economists have also begun to make important contributions in this area. Lawyers writing in this area tend to focus on the fiduciary duties of the directors and the need to have independent directors, who will represent the interests of minority shareholders (see for instance, Srivastava and Mock, 2000, who focuses on this aspect) without linking it to the role of the capital markets, whereas economists see good corporate governance as a means of improving the efficiency of the capital markets, so that sustainable economic growth can occur in this era of increasingly global capital markets (The Economist, 7th April 2001, pp. 1-18).

The economic view of corporate governance is that it has an impact on the vitality and integrity of the market system. According to Guillen (2000), corporate governance plays a key role in any economy by providing a framework for the division of labour and financial results in the firm. He reiterates the fact that a well-functioning corporate governance system can contribute to economic efficiency and perhaps even social equity whereas, on the other hand, a poorly conceived system can wreak havoc in the economy by misallocating resources or failing to check opportunistic behaviour by agents, which precipitates serious political risk for the ruling elites. Such observations have initiated discussions on corporate governance in a number of countries around the world, thus leading to the introduction of the globally recognised OECD principles of corporate governance.

At a microeconomic level, therefore, the economic view of corporate governance is that managers of the company are the custodians of the assets and their prime responsibility is to use those assets efficiently in the pursuit of the firm's objectives. That is, economists believe that creating value for the shareholders is the essence of good corporate governance. In an ideal world of corporate governance, the managers would also enjoy the freedom to manage in meeting the shareholders expectations. There has been research which suggests that investors value corporate governance in both developed and emerging economies. Thus, the certification of the veracity of the published corporate governance would also be given a value premium.

Despite the workings of the market mechanism and the premium investors are willing to pay for good corporate governance, recent high profile cases of governance failure (Enron and WorldCom) led to corporate misconduct whereby the public, employees and pensioners have lost billions in investment and savings at the expense of gains to insiders, much of it by fraud. These events have demonstrated that the current corporate governance mechanisms have not kept up with the free-market philosophies of the economists. Therefore, the development of robust governance tools and incentive structures in light of rapid changes in the markets and financial innovation are needed for limiting present inconsistencies and confusion assumes prime importance, despite the attractions of agents' incentive compensations.

The legal viewpoint of corporate governance is that it refers to the procedures and rules, explicit and implicit, that provide the incentive framework for companies to attract financial and human capital, perform efficiently and avoid corruption. These rules have evolved over time, and are still evolving in response to corporate failures and systemic crisis (World Bank, 1999). Those subscribing to such an approach are of the view that corporate governance is a modern expression on an issue which companies have been facing for decades i.e., that of "accountability". Corporate governance is seen as how those entrusted with day-to-day management of a company's affairs are held accountable to shareholders and other stakeholders by ensuring that the organisation has appropriate corporate structures to underpin such accountability. 
The societal (social) viewpoint of corporate governance is that it is about communications i.e., how the company presents itself to the wider world - shareholders, potential investors, employees, regulations and other groups with a legitimate interest in its affairs. This view rests on the premise that, whilst corporate governance is principally concerned about the relationship between shareholders, management and the board in determining the direction and performance of the corporation (Monks and Minow, 2001, p.1), its scope should be even broader, encompassing other issues like the ethical standards, crisis management, reporting to stakeholders not only in strict compliance with legal issues in a country, but also in terms of social responsibility.

Despite the varied approaches of the discipline based models, the core view of corporate governance indicates that it relates to how the various constituencies that define the business enterprise serve, and are served by, the firm. Thus corporate governance is concerned with the relationship between shareholders and other stakeholders, the board of directors and management. Explicit as well as implicit relationships between the corporation and its employees, customers, creditors, suppliers, and host communities (and the dynamics of the relationships among these constituencies) thus fall within the boundary of an embracing definition of corporate governance. Some principles of corporate governance are of universal value, most importantly, transparency and disclosure principles. Thus corporate governance is about balancing two objectives. One is to promote business enterprise by enhancing the capability of its reputation to generate current and future business (economic), and at the same time assuring accountability of business to shareholders (legal) and to society (social).

As we have discussed, corporate governance models differ widely due to differences in the disciplinary (silo) approach. Another reason for differences is the business context within which these models develop. The basic contextual factor is shareholder concentration, which not only includes the percentage holdings of various stakeholder groups in terms of the ownership of the total number of shares that are publicly traded, but also includes aspects of concentration in terms of the power of the CEO, shareholder identity, liquidity of the market and level of mutual shareholdings.

These contextual factors have resulted in the development of different models of corporate governance around the sphere. Among the developed countries, the main ones have been seen to be those of the English Speaking Countries, with discrete controls, and on the other hand German and Japanese models, which reflect a more concentrated ownership structure. Developing countries like India have a corporate governance system which is a hybrid of the arms-length market-based systems of UK and USA and the insider-dominated-bank-based systems of Germany and France (Sarkar and Sarkar, 2000). Two corporate governance models are analysed below - The Anglo-Saxon and The Continental European models.

In the Anglo-Saxon or market-based system, markets play a decisive role. The government is at arm's length relationship with corporations while creating a strong competitive environment in which firms operate. Firms are put under pressure in the product and factor markets, whilst managers are put under pressure in the managerial labour markets. The belief underlying this system of corporate governance is that competition and working of the market system will force companies and managers to act truly in the best interest of shareholders (Carati and Rad, 2000),. This model of corporate governance is more prominent in the U.S. and the U.K.

However, when it comes to the performance measurement, the role and values of other stakeholders need to be understood. One of the tasks of the board is to determine the nature of other stakeholders and their importance compared to shareholders. The second model considered is The Continental European model which is also known as the stakeholder model. The focus of the Continental model is on the need to satisfy societal expectations, in particular, the interest of employees and other stakeholders (suppliers, creditors, tax authorities and the community). This view dominates in continental Europe (particularly Germany, France and the Netherlands) and in certain countries in Asia (Gregory, 2000). (Please refer to Ooghe and Vuyst (2001) and Appendix 2 for the differences between the abovementioned corporate governance models).

It can be seen, therefore, that each disciplinary approach has different focus aspects in terms of control and governance procedures, and that those contextual factors such as stakeholder concentration plays a part in what control mechanism is chosen for good governance. A holistic corporate governance framework therefore should 
combine these two approaches, and such a model is presented in Figure Three. The area of risk management must work with all three approaches based on the prevailing contextual factors to ensure the reputation maintenance and enhancement of their organisation.

A number of contextual factors are elaborated in Figure Three. For example, when shareholder concentration is low (i.e. no one stakeholder group - including the CEO - controls the company) then good governance can be achieved legally via the proper preparation and certification of financial statements and economically via capital market efficiency. If social issues are raised these would pertain mainly to environmental issues in that all group of stakeholders are ultimately affected by the quality of the societal/global environment. When there is more stakeholder concentration (medium level) then legally, accountability issues arise where corporate governance procedures are required to ensure that the organisation has appropriate corporate structures are in place so that those entrusted with day-to-day management of a company's affairs are held accountable to shareholders and other stakeholders. Issues such as internal audits and minority interests arise in such situations. The economic incentives on the managers are incentive based, with good performance (high rates of return) appropriately rewarded by the stakeholders. Some social issues will emerge at this point whereas there will emerge consensus of opinion amongst some stakeholder groups on issues such as ethics, environment, child labour etc. (for example these have resulted in the establishment of ethical investment funds in Australia by Rothschild Australia, Westpac, Tower, AMP, HESTA, UniSuper and VicSuper).

Figure Three: The Contextual Factors of a Holistic Corporate Governance Model

\begin{tabular}{|l|l|l|l|l|}
\hline \multirow{4}{*}{$\begin{array}{l}\text { STAKEHOLDER } \\
\text { CONCENTRATION }\end{array}$} & HIGH & $\begin{array}{l}\text { Fiduciary Duties } \\
\text { of Directors }\end{array}$ & Shareholder Value & $\begin{array}{l}\text { Triple-Bottom Line } \\
\text { Accounting }\end{array}$ \\
\cline { 2 - 5 } & MEDIUM & $\begin{array}{l}\text { Accountability of } \\
\text { Managers and } \\
\text { Internal Audit }\end{array}$ & $\begin{array}{l}\text { Economic } \\
\text { Incentives to } \\
\text { Managers }\end{array}$ & $\begin{array}{l}\text { Social Audits of } \\
\text { Managerial Actions }\end{array}$ \\
\cline { 2 - 5 } & LOW & $\begin{array}{l}\text { Financial } \\
\text { Statement } \\
\text { Controls }\end{array}$ & $\begin{array}{l}\text { Capital Market } \\
\text { Efficiency }\end{array}$ & Environmental Accounting \\
\cline { 3 - 5 } & LEGAL & ECONOMIC & SOCIAL \\
\cline { 3 - 4 } & \multicolumn{4}{|c|}{ FOCUS OF RISK MANAGEMENT } \\
\hline
\end{tabular}

Where there is high stakeholder concentration, then less reliance can be placed legally on financial statements and other accountability and audit measures. The recent examples of spectacular corporate collapses have been due mostly to significant concentration of power with the CEO. Thus the failure of the firms can, at least in part, be attributed to corporate governance (designed to work well within less concentrated contexts) being unable to cope in high stakeholder concentration environments. That inappropriate corporate governance mechanisms could lead to corporate failure represents a waste of scarce resources within the economy. Also we cannot overlook the inconvenience, or sheer misery, that high profile collapses cause at the level of the individual as a result of the big corporate collapses. Sporadic and reactionary attention paid to corporate governance, role and activities of the board of directors in controlling and monitoring of the management of the firm is insufficient. Implications from Enron have thus been noted - need for the board to be active, involved, knowledgeable, and be willing to take on management and also bear responsibility for performance of the firm.

At first glance it therefore appears that when stakeholder concentration is high, more specific legal controls are required. The essential common points in the various codes or guides put out around the world deal with such specific controls may be noted:

- That corporate governance is a means of ensuring that the exercise of economic power by the corporate sector is grounded in accountability - whether that is accountability to shareholders or to the broader community;

- That boards have supervisory and managerial functions;

- That there should be separation between the supervisory and managerial roles. 
Some of the practices suggested in the codes for that purpose include for example:

- $\quad$ Separation of the roles of the Chairman and CEO;

- $\quad$ The appointment of independent directors; and

- $\quad$ The use of board committees, particularly in the areas where the interests of management and the interests of the company may come into conflict - e.g. audit, remuneration and nomination.

Most codes also call for comprehensive disclosure to shareholders on all aspects of corporate governance, in particular, on the issues of director and executive remuneration, independence of directors, and share ownership. All of the above would require some form of 'certification' from an external auditor.

In terms of economic focus when stakeholder concentration is high, then maximising shareholder value must be the core focus as it is the shareholders that bring a company into existence and ultimately it is the shareholders that can wind down the company. Other stakeholder concentrations must be satisfied within the context of long-term shareholder wealth. Good governance structure should ensure that the shareholders interest does not by itself preclude protections to other stakeholders.

It must be noted at this point there are those who still regard the recent increase in attention to governance as a fad. As this group sees it, the stock of a well-governed company may be worth more simply because governance is such a hot topic these days. Believing in the value of corporate governance should no longer be a question of faith. Ratnatunga and Ariff (2005) state that some investors will pay a significant premium (ranging from 15\%-28\% in different countries) for good governance. Therefore, although governance is more important in some circumstances than in others, and more important to managers of some types of funds than others, it remains clear that good board governance can serve as a tool for attracting certain types of investors, as well as influencing what they will pay for stock.

Investors expect good corporate governance. There are three main reasons why investors will pay a premium for good governance, and the associated certification of such. Some believe that a company with good governance will perform better over time, leading to a higher stock price. This group is primarily trying to capture upside, long-term potential. Others see good governance as a means of reducing risk, as they believe it decreases the likelihood of bad things happening to a company. Also, when bad things do happen, they expect well-governed companies to rebound more quickly. An earlier 1996 a survey by McKinsey reported that investors surveyed would place an average premium of $11 \%$ on stocks of well-governed companies. The reciprocal, of course, is that investors will punish individual companies, or broader markets, or even whole national capital markets, for serious governance deficiencies (recall the marked down values of Japan and ASEAN economies in the late 1990s). In the new century, these cautionary studies cannot be dismissed as academic over-cry. We are living through this reality in the most sophisticated and developed economies the world have ever seen (OECD, 1999). In Wall Street parlance, smart investors discount for fraud, meaning they now assume dishonesty in corporate auditing and have priced in it when they calculate a stock's value. Others have fled the market entirely. (Holland, 2002).

When stakeholder concentration is high, triple-bottom bottom line accounting is required in the social context, where companies are recognised as existing to create wealth or long-term value on an economically, socially and environmentally sustainable basis, i.e. 'sustainable value creation'. This issue will not be dealt with in this chapter. Instead we will deal specifically with the issue as if there are corporate governance measurement available that can be applied within a high stakeholder concentration context that can safeguard shareholder value without having to resort to rules and codes of conduct put forward by the legal discipline.

The ultimate value to an organisation in meeting its corporate governance responsibilities, be they legal, economic or social, would be the result of contextual capability that arises when the required preconditions are present (see Figure One). For example, in ensuring that the Directors comply with their Fiduciary Duties requires not only a reliable executive information system (with such tangible assets as up to date computers and dedicated software), but also intangible assets such as properly qualified, knowledgeable and independent directors. Thus the costs incurred by an organisation in investing in such tangible and intangible assets, must be compared with the 
benefits (consequences) in terms of current and future sales that such investments will bring due to an enhanced Brand/Reputation capability.

\section{COMMUNICATION, EMPOWERMENT AND RISK MANAGEMENT}

A significant amount of research exists on the differences between the "Western" and "Japanese" management control systems. It has been argued that whilst the Western management control systems have "truth and accuracy" as their reporting objectives, the Japanese control reports are designed to elicit "behaviour changes" of managers and employees, sometimes at the expense of accuracy. Both approaches have significant downsides. The Western approach often results in information understanding with very little behaviour modification by managers and employees. In contrast, the Japanese systems obtain behaviour modification, but very little information understanding.

This paper takes the view that the cost of both baring risk and sharing risk can be reduced if employee behaviour can be modified in the long-run by creating a holistic global ownership culture where behaviour is changed due to understanding the strategic impact of the information that is presented to such an employee. This is achieved only by ensuring that all participants know the "rules" of the game, know how the "score" is kept, and ultimately participate passionately in the "game" (of reputation and value enhancement) that is being played.

In most companies, employees are likened to the American tourist who comes to Australia to watch a game of "cricket". He or she is a participant in the overall atmosphere of the game, but his or her own enjoyment and motivation to keep watching is significantly reduced by not knowing the rules, what strategies the teams are employing, how to keep the score, or for that matter, who is winning!

Transferring this analogy to an organisation, if employees do not know what are the organisation's risk management strategies are, or the measures used to evaluate good and bad risk practices, then they would have no idea if the organisation they belong to is enhancing its reputation or not. Consequently, they will not be motivated to work towards the goal of organisational success. The key aspects of this open-book approach are that it:

- $\quad$ shares a broad array of financial and other information with employees,

- $\quad$ trains employees to become more business literate,

- empowers them to use the information in their work, trusting them as partners in the reputation enhancement process, and

- $\quad$ rewards them when the company is successful in both maintaining and enhancing its reputation (and thus its value).

One can see that accounting plays a vital role in the implementation of such an open-book risk management and communication policy, as most corporate performance measurements are ultimately accounting-numbers based. Measures such as profit, return on investment (ROI), earnings per share (EPS), and the price-earnings ratio (P/E), are all derived from the financial accounting statements. If rank-and-file employees are provided these numbers, then they would need to understand and interpret these measures. Thus, training employees first in accounting (i.e. the language of business), and subsequently in other organisational scorecards incorporating non-financials, becomes an important part of open-book management.

It has now been seen, however, that financial and non-financial information on its own will not motivate such knowledge workers to strive to achieve the strategic objectives of the organisation in a globalised environment. In the emerging 'influential-economic' paradigm, the role of accounting is to empower these knowledge workers i.e., train them to have knowledge understanding and then provide them with all the necessary information to steer their organisations successfully in the globally competitive waters.

Risk management using an open-book policy is, therefore, essentially not only teaching employees how to read organisational scorecards and enabling them to judge if their team is winning or not, but to be provided with all of the information (financial or otherwise) and responsibility required to be a team player in the game of business. 
Jan Carlzon (1989), the President of the Scandinavian Airline System, summarises this approach excellently in his book 'Moments of Truth' as follows:

- $\quad$ Everyone needs to know and feel that he (or she) is needed.

- $\quad$ Everyone wants to be treated as an individual.

- Giving someone the freedom to take responsibility releases resources that would otherwise remain concealed.

- An individual without information cannot take responsibility; an individual who is given information cannot help but take responsibility (Carlzon, 1989).

The proper implementation of empowered open-book risk management requires, therefore, something more than training employees how to interpret financial and other scorecards. It requires a fundamental change in the traditional way in which managers operate their business; i.e. by providing both information and responsibility for employees to think and act like owners. Essentially, such managers are committed to empowering their subordinates to use the information provided, and act like the owner of their niche in the organisation.

Employees will act as owners, only if they share the organisation's goals, and are rewarded when these goals are achieved and the company is considered successful (Barton, et al., 1998).

The inescapable logic of open-book empowerment accounting is, therefore, that employees are likely to share organisational goals when they:

- Understand how an organisation's assets combine to provide a capability to create value;

- $\quad$ Understand the techniques used to measure how much value was created;

- $\quad$ Are provided regularly the scorecards that show how value was enhanced (or lost);

- $\quad$ Are empowered to act in a manner that will improve the value-creating capability of the organisation; and

- $\quad$ Share in the rewards when the organisation does well.

If measures are meant not only to 'inform' but also influence, then the accountability focus of accountants should also be widened. Research is therefore required to develop measurements, in order to discharge all potentially significant accountabilities. Multiple measurement-units and reporting formats need to be developed to cater for the conflicting accountability demands of different internal and external constituencies. This will require both leading and lagging measurements as discussed earlier, and all of the varied informational categories presented in Figure Four.

Empowered Risk Management extends the philosophies of an open-book style of management into the nonfinancial arena, in order to empower employees into taking a holistic approach in creating an "ownership culture". If it is expected that employees take crucial decisions that affect the company in a "moment of truth", then they should be made aware of not only the financial impact of their decisions but also the non-financial, i.e. communicating the overall picture. In order to provide such information, organisations must provide both past and future oriented information, both financial and non-financial information, and both numeric and textual information, and also train their employees on analysing and interpreting such information.

The ultimate value to an organisation of having such empowered information flows would be the result of contextual capability that arises when the required preconditions are present (see Figure One). For example, to ensure that an organisation's workers are motivated via the development of an 'ownership culture', they must believe they have access to all information flows required to do their job in an empowered manner. This will require not only tangible assets such as computer terminals and software that can handle different levels of 'openness' in information flows), but also intangible assets such as properly trained employees who can read financial statements and other organisational scorecards. Thus the costs incurred by an organisation in investing in such tangible and intangible assets, must be compared with the benefits (consequences) in terms of current and future sales that such investments will bring due to an enhanced Brand/Reputation capability of having such a motivated workforce. 
The following Figure Four indicates the information depth required for such empowered communication.

Figure Four: The Empowered Risk Management Information Scope

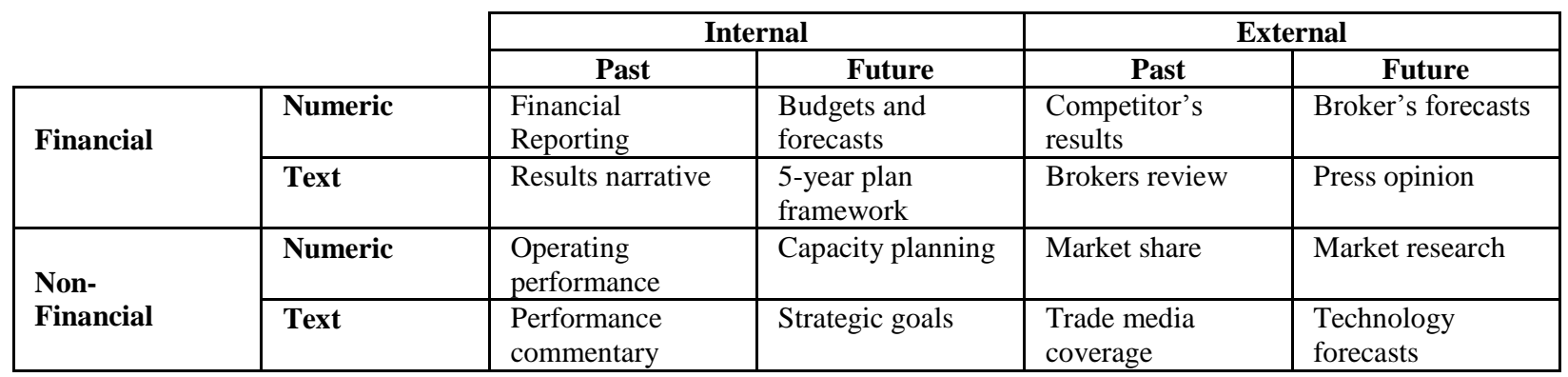

\section{STRATEGIC RISK MANAGEMENT AND AUDIT CERTIFICATION}

Subramaniam and Ratnatunga (2003) state that to ensure adequate risk management, strategic information reports should be developed to link long-term or strategic goals of an organisation with performance evaluation outcomes, and therefore that appropriate strategic audit techniques would also be required.

A Strategic Audit is far different from the common perception of financial audits. It is a continuous evaluation of all the strategic functions of any success-seeking firm. Due to such a wide scope, strategic audit issues are pertinent to management accountants, business analysts, audit directors, senior managers and executive-level management, as well as those aspiring to become someone who oversees audit, security, compliance and control functions. For example, the scope of the audit will certainly be different if Strategic Balance Sheets (see Figure Two) are adopted by companies, as the more traditional audit will need to be expanded to cover future oriented strategic audit based certifications, such as giving an opinion on the valuation approaches used to value intangible and tangible asset combinations that enhance an organisation's strategic capabilities.

Some examples of the wide-scope of strategic audits are given below.

Stakeholder Audit: This audit is to assess the organisation through the eyes of the stakeholders. Stakeholders usually fall into four groups: shareholders, customers, employees and suppliers. In fact, anyone interested in the success of the organisation is a potential stakeholder who have various incentives to help it, thus it pays to know them well. Each group has a different reason why they want the organisation to be successful. Shareholders want a return on their investment, customers benefit from the organisation's products or services, employees earn income and suppliers want to sell the organisation more. When the organisation prospers, they prosper. The organisation's stability and growth is their stability and growth, thus this is a key audit area for corporate governance.

Marketing Audit: This is a comprehensive examination of the company's marketing environment, objectives, strategies, and activities with a view to determining problem areas and opportunities and recommending a plan of action to improve the company's marketing performance.

Productivity Audit: This audit explains the complexity of the productivity concept, and discusses the evaluation of productivity in a strategic context. This increases the chances of increasing productivity in real terms, rather than improving efficiency at the expense of strategic goals.

Logistics Audit: This audit includes the best practices of companies with world-class logistics systems, and suggests tools for measuring a company's performance in comparison to logistics leaders. 
Service Management Audit: This audit provides information about using service resources effectively, measuring the quality of service management, and assessing a company's ability to recover in the face of service failure.

Customer Satisfaction Audit: This audit outlines the critical aspects of system-wide customer satisfaction, and provides tools for measuring performance along those lines.

Cost of Quality Audit: The term "cost of quality" actually refers to the cost of not ensuring high quality. This audit provides a way of understanding the amount of income that is lost as a result of poor quality, along with suggestions for reducing that cost and improving quality.

Environmental Audit: This audit describes how managers can determine which environmental standards should be targeted for a given organization, and provides a model for auditing performance in terms of those standards.

Leadership Audit: This is a method of determining which competencies are required for leadership success in a given organization, and presents tools for measuring the performance of the company's employees in terms of those competencies. It stresses the need to develop leadership at all organizational levels, and suggests an outline for developing personal improvement plans.

Culture Audit: This audit provides a tool to uncover a company's culture, and provides tips on using that understanding to implement change more effectively.

Corporate Identity Audit: This audit provides insight into determining the effectiveness of a current identity, and outlines a way of assessing whether an identity should be changed, and what is the direction of those changes.

Corporate Longevity Audit: This audit is undertaken to ensure that an organisation not only maximizes the value of the existing products and services, but also simultaneously develops their replacements that will earn future income. Many companies rest on their current successes, today's breadwinners, without realizing it is only a matter of time until their current products and services are obsolete.

Corporate Flexibility Audit: This audit considers the processes in place to hire the right people the first time and get them up-to-speed as fast as possible. The checks on the systems created to bring people together (e.g. work presentations to non-related staff, office layout) and encourage good working relationships.

Information Security Audit: This audit provides a framework for systematically evaluating an information system's security.

Strategic Alliance Audit: This audit suggests ways of determining whether or not a particular alliance option is suitable for a given company, and provides ideas for rejuvenating alliances that may be functioning at sub-optimal levels for both manufacturing and service firms.

Technology Audit: This audit provides insight into determining which technologies should be priorities for a company given its strategy. It also provides tools for determining what aspects of the company can be called technologies, and a system for breaking technologies down into component parts.

Due to such a wide scope, strategic audit issues are pertinent to management accountants, business analysts, audit directors, senior managers and executive-level management, as well as those aspiring to become someone who oversees audit, security, compliance and control functions. Similarly, Strategic Audits could not only dwell on highly technical matters, but also provide management and other stakeholders a perspective on information systems and technology issues at the strategic level. This will in turn promote good corporate governance by enabling managers to make well-informed planning and resource decisions that will ultimately enhance the value of the organisation. 


\section{SUMMARY}

This paper argues that the overriding reason for governance is ultimately the safeguarding of an organisation's reputation, and that this requires an integrated approach where the 'accountees' (corporations), and its investors and regulators are provided with appropriate information by the 'accountors', i.e. the accounting profession. It also argues that although the current professional accounting standards result in financial statements that are not adequate for the proper governance, an integrated approach can be taken where reputation risk can not only be managed and valued; it can also be incorporated in these financial statements.

In terms of financial reporting, there should be no controversy from the 'accountors' that financial statement should provide its readers (the 'accountees') with all material information that is both relevant and reliable. The relevance of intangibles has not usually been questioned, but the reliability of valuations, especially with relation to the valuation of its capabilities, has often been questioned.

We have argued that for proper risk management, an organisation should measure the capability of its reputation to generate value beyond its financial performance, and help managers integrate processes and resources into the organisation's overall success - an essential step toward competing in a knowledge-based environment. Just as traditional accounting tools helped managers accumulate and allocate an organisation's financial resources, a new conceptual framework is required for managing its capabilities, including its intellectual capital.

The measurement of an organisation's reputation capability value is a fast-growing part of the knowledge management market. It has many attractions, at least in theory. The process of drawing up a Strategic Balance Sheet focuses managers on the capabilities enhanced by such tangible and intangible asset combinations. It also helps managers and investors to visualise the role of reputation assets in creating organisational value. These new measurement systems all use similar measures of human capital, customer relationships and structural capital, for example in the latter case, those embedded in organisational relationships and joint-ventures.

The paper argues that the capability of an organisation to govern itself adequately and protect itself against potential threats to its reputation requires informational measures that evaluate the impact of the actions of corporations on the environment, and on society. In the modern firm, therefore, Risk Management is very concerned with managing three "bottom lines", namely the capability of an organisation to maintain and enhance its reputation via its economic, environmental and social performance, and that this will ultimately lead to the maintenance and enhancement of its stakeholder value.

Once such new measures and reports are devised, there arises the need to audit them. This paper highlights the importance of future oriented strategic auditing and how the various types of strategic audits have implications for attesting the strategic reputation-based capability values of the organisation as a going concern.

Finally, it is argued that knowledge and information is of no incremental economic value unless it is used to create value. In today's globalised business environments such value is created by knowledge worker employees working in a shared ownership culture who understand the information that is presented to them and are motivated by this understanding. There is no doubt a risk manager must be up to the task of championing the new culture.

\section{REFERENCES}

1. Barton, T.L., Shenkir, W.G. and Tyson, T.M. (1998), Open-Book Management: Creating and Ownership Culture, Financial Executives Research Foundation Executive Report, Vol. 5, No.2, March.

2. Carati, G. and Rad, A.T., (2000), Convergence of Corporate Governance Systems, Managerial Finance, Vol. 26, No. 10, pp. 66-83

3. $\quad$ Carlzon, J. (1989) Moments of Truth, Harper and Row, New York.

4. Demirag, I.S., Wright, M. and Sundarsanam, S., (2000), Corporate Governance: Overview and Research Design, British Accounting Review, Vol. 32, pp. 341-354

5. $\quad$ Economist, (2001), The Economist Newspaper Ltd., London. 7th April, pp. 1-18 
6. Gregory, H.J., (2000), The Globalization of Corporate Governance, in Weil, G, and Manges L.L.P, http://rru.worldbank.org/documents/globalisation_of_corporate_governance.pdf, accessed on $26^{\text {th }}$ September, 2003

7. Guillen, M.F., (2000), Corporate Governance and Globalisation: Is there Convergence across Countries? The Wharton School and Department of Sociology, University of Pennsylvania.

8. Holland, T. (2002) Corporate Accountability: World Con Far Eastern Economic review: July 11, p. 18,

9. Kohler, A. (1991), Australia's Accountants have a lot to Answer for, The Sunday Age, Money Section, 30 September, pp 1.

10. Monks, R. A. G. and Minnow, N., (2001), Redesigning Corporate Governance Structures and Systems for the Twenty First Century, Corporate Governance: An International Review, Vol. 9, No. 3, pp. 142-147.

11. OECD (1999), Report on the Financial Aspects of Corporate Governance, Organisations for Economic Cooperation and Development, Gee \& Co., London.

12. Ooghe, H., and Vuyst V.D., (2001) The Anglo-Saxon versus the Continental European Corporate Governance Model: Empirical Evidence of Board Composition in Belgium, Vlerick Leuven Gent Management School, http://www.vlerick.be/research/workingpapers/2001-6.pdf, accessed on $6^{\text {th }}$ September, 2003

13. Ratnatunga, J. and Ariff, M. (2005), Towards a Holistic Model of Corporate Governance, Journal of Applied Management Accounting Research, Vol 3, No.1, pp. 1-15.

14. Ratnatunga, J., Gray, N. and Balachandran, K.R. (2004) CEVITA ${ }^{\mathrm{TM}}$ : The Valuation and Reporting of Strategic Capabilities, Management Accounting Research, 15(1) March, pp. 77-105.

15. Roland, G., (2000), Corporate Governance Systems and Restructuring: The Lessons from the Transition Experience, www.worldbank.org/research/abcde/washington_12/pdf_files/roland.pdf, (accessed on 5th September, 2003)

16. Sarkar, J. and Sarkar, S., (2000), Large Shareholder Activism in Corporate Governance in Developing Countries: Evidence from India, International Review of Finance, Vol. 1, No. 3, pp. 161-194.

17. Srivastava, R. P. and Mock, V., (2000), Belief Functions in Accounting Behavioral Research in Advances in Accounting Behavioral Research, Vol. 3, JAI Press Inc., Stamford, Connecticut, pp. 225-242.

18. Subramaniam, N. and Ratnatunga, J. (2003) Corporate Governance: Some Key Challenges and Opportunities for Accounting Researchers, Journal of Applied Management Accounting Research, 1(2), pp $1-8$.

19. Tweedie, D. (1991), Accounting Standards: Their role in Policing of Society - The Growing Crisis of Confidence, Discussion Paper Series 3/91, School of Accounting, Monash University, pp 1-45.

20. Webb, L., Ratnatunga, J. and Mudalige, N. (1991) Counting and Analysing Corporate Failure in Australia: A Ten Year Study, Proceedings, AAANZ Annual Conference Proceedings, Queensland University of Technology, Brisbane, pp 354-361

21. World Bank (1999) Corporate Governance: A Framework for Implementation - Overview http://www.worldbank.org/html/fpd/privatesector/cg/docs/gcgfbooklet.pd, accessed on $6^{\text {th }}$ September, 2003, www. World Bank.org 


\section{NOTES}

